\title{
Design and experimental results of the 1-T Bitter Electromagnet Testing Apparatus (BETA)
}

E. M. Bates, W. J. Birmingham, and C. A. Romero-Talamás

Citation: Review of Scientific Instruments 89, 054704 (2018); doi: 10.1063/1.4997383

View online: https://doi.org/10.1063/1.4997383

View Table of Contents: http://aip.scitation.org/toc/rsi/89/5

Published by the American Institute of Physics

\section{Articles you may be interested in}

Novel plasma source for safe beryllium spectral line studies in the presence of beryllium dust

Review of Scientific Instruments 89, 053108 (2018); 10.1063/1.5025890

CVD diamond detector with interdigitated electrode pattern for time-of-flight energy-loss measurements of low-energy ion bunches

Review of Scientific Instruments 89, 053301 (2018); 10.1063/1.5019879

A versatile tunable microcavity for investigation of light-matter interaction

Review of Scientific Instruments 89, 053105 (2018); 10.1063/1.5021055

Detector for positronium temperature measurements by two-photon angular correlation

Review of Scientific Instruments 89, 053106 (2018); 10.1063/1.5017724

Fast resolution change in neutral helium atom microscopy

Review of Scientific Instruments 89, 053702 (2018); 10.1063/1.5029385

Two-degrees-of-freedom piezo-driven fast steering mirror with cross-axis decoupling capability

Review of Scientific Instruments 89, 055003 (2018); 10.1063/1.5001966

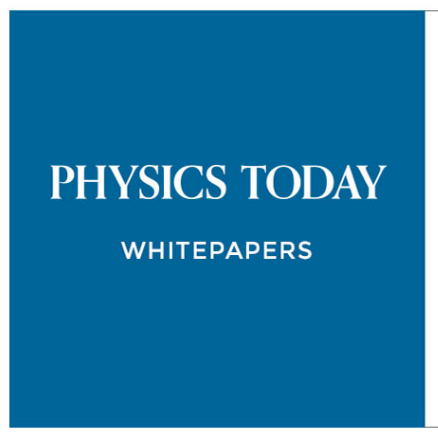

MANACER'S GUIDE

Accelerate R\&D with

Multiphysics Simulation

\section{READ NOW}

PRESENTED BY

$\checkmark \subset \bigcirc M S O L$ 


\title{
Design and experimental results of the 1-T Bitter Electromagnet Testing Apparatus (BETA)
}

\author{
E. M. Bates, ${ }^{\text {a) }}$ W. J. Birmingham, ${ }^{\text {b) }}$ and C. A. Romero-Talamás ${ }^{\text {() }}$ \\ Mechanical Engineering Department, University of Maryland, Baltimore County, Baltimore, \\ Maryland 21250, USA
}

(Received 24 July 2017; accepted 17 April 2018; published online 9 May 2018)

\begin{abstract}
The Bitter Electromagnet Testing Apparatus (BETA) is a 1-Tesla (T) technical prototype of the $10 \mathrm{~T}$ Adjustable Long Pulsed High-Field Apparatus. BETA's final design specifications are highlighted in this paper which include electromagnetic, thermal, and stress analyses. We discuss here the design and fabrication of BETA's core, vessel, cooling, and electrical subsystems. The electrical system of BETA is composed of a scalable solid-state DC breaker circuit. Experimental results display the stable operation of BETA at $1 \mathrm{~T}$. These results are compared to both analytical design and finite element calculations. Experimental results validate analytical magnet designing methods developed at the Dusty Plasma Laboratory. The theoretical steady state maxima and the limits of BETA's design are explored in this paper. Published by AIP Publishing. https://doi.org/10.1063/1.4997383
\end{abstract}

\section{INTRODUCTION}

The Bitter Electromagnet Testing Apparatus (BETA) is a 1-Tesla (T) technical prototype of the $10 \mathrm{~T}$ Adjustable Long Pulsed High-Field Apparatus (ALPHA). These magnets are water-cooled resistive Bitter magnets designed for steady state but are operated on long-pulsed time scales due to the energy capacity of their battery banks. BETA has been designed and constructed at the Dusty Plasma Laboratory (DPL) at the University of Maryland Baltimore County (UMBC). This magnet system is intended to be a scalable system design that will aid in the production of ALPHA, which will become a novel tool for studying magnetized dusty plasmas. ALPHA is currently designed with a $15 \mathrm{~cm}$ diameter bore and will consume $\sim 11 \mathrm{MW}$ of electrical power. BETA is a low-powered magnet, and therefore its thermal design does not scale to ALPHA. The thermal design of ALPHA will produce a uniform conductor temperature distribution, a characteristic of high-powered Bitter magnets, for efficient current distribution and minimizing localized stresses. With its present power and cooling subsystems, BETA can achieve a long-pulsed magnetic field of $1 \mathrm{~T}$ in a 3-cm diameter bore. The magnet core design of BETA was determined by analytical design methodologies developed at DPL. ${ }^{1,2}$ Presented here are the essential design specifications and analyses of BETA including the magnet core design, fabrication processes, scalable subsystems, and initial experimental results. The experimental results of BETA are used to validate and verify DPL design methodologies.

Bitter magnets consist of conducting and insulating arcs, both of which have a pattern of axial cooling holes. The magnet's coil is constructed by stacking Bitter arcs to arrange a helical current path. A fully stacked coil will also align to form axial cooling channels from the cooling hole pattern. To

\footnotetext{
a)Electronic mail: evbates1@umbc.edu

b) Electronic mail: birming2@umbc.edu

c)Electronic mail: romero@umbc.edu
}

generate the magnetic field, a voltage is applied across the coil. Current travels through the helically stacked conductors and produces an axial field inside the magnet's bore. High magnetic fields require large electrical currents that significantly heat the Bitter conducting arcs. To remove such heat, prechilled cooling liquid is transported at high velocities through the cooling channels in the magnet's core. The convective heat transfer dissipates heat at a rate fast enough to prevent the magnet from melting. Francis Bitter invented this magnet concept in the 1930s. ${ }^{3}$ Here, we demonstrate the development of Bitter magnet technology at DPL for studying the phenomenon of magnetized dusty plasma.

\section{A. Motivation}

Dusty plasma is a four-component system consisting of electrons, ions, neutral atoms, and dust particles. The objective is to thoroughly magnetize all components in the system with dust grains of a sufficient size and mass to be optically captured with conventional optics. ${ }^{4}$ Experiments have yet to fully magnetize dust particles with diameters on the order of a few microns.

Potential research applications of magnetized dusty plasmas in a high magnetic field include: charging mechanism of the dust particles, dust-dust interactions, development of plasma sources and diagnostics, and achieving a stable plasma discharge in a high magnetic field. ${ }^{5}$ Additionally, there are applications to both manufacturing and research plasma disciplines, from nanoparticle fabrication and semiconductor contamination to understanding radioactive dust contamination in fusion plasma devices.

Future dust magnetization at DPL will be realized inside the 15-cm diameter bore of ALPHA at a uniform 10 T field. ${ }^{6}$ The magnet's bore needs to be large enough to house the plasma vacuum chamber and diagnostics needed to create, stabilize, and record a plasma event. The bore size of the magnet must be constrained to the dimensions of a cylindrical chamber constructed at $\mathrm{UMBC}$, which is $15 \mathrm{~cm}$ in diameter and 
$1.2 \mathrm{~m}$ in length. The magnet's bore size is the most important driving factor of the magnet's design. ALPHA will be constructed with a minimum diameter to allow: diagnostic access, $1-\mu \mathrm{m}$ diameter dust grains, and dust confinement between electrodes at radius $5 \mathrm{~cm}$ in an $\boldsymbol{E} \times \boldsymbol{B}$ field with approximately $2.5 \mathrm{~V} / \mathrm{m}$ and $10 \mathrm{~T}$, respectively.

BETA, presented here, is being used to develop new Bitter magnet design procedures, to master magnet engineering, and to recognize complications that could affect the ALPHA magnet project.

\section{MAGNET DESIGN AND ANALYSES}

\section{A. Analytical design methodology}

Three methods have been developed at DPL to assist in evaluating a variety of Bitter magnet configuration geometries. The design process is iterative and consists of three sets of essential parameters: the magnetic field, temperatures, and mechanical stresses. The design of the magnet first progresses through an electromagnetic optimization where the coil's magnetic field and conductor's resistivity (at an average conductor temperature) are constrained by user-defined constants. The magnet's core design parameters (geometrical and electrical) are optimized to minimize the coil's electrical power.

The magnet core then moves to the thermal design step, where elongated cooling holes are placed radially and staggered in the same convention as the Florida-Bitter design. ${ }^{7}$ The conductors' cooling hole wall temperatures are analytically calculated to predict the temperature profile of the Bitter arc conductors as a function of the optimal operating current. ${ }^{1}$ Cooling holes are placed to produce an approximated average conductor temperature that results in the prescribed conductor resistivity of the electromagnetic optimization. If the water's temperature from the cooling channels' outlets are below boiling and peak temperatures on the conductors do not change the mechanical properties of the material, then the design moves to the mechanical stress stage.

The coil design is then evaluated using ANSYS finite element analysis (FEA) to determine if the stresses from magnetic forces will surpass the coil's yield strength. BETA's design was chosen to have a factor of safety (FOS), material yield strength over maximum Bitter arc stress, of 10 or greater since this is the first Bitter magnet built at DPL. The deformations and strains of the design are assessed simultaneously. At any stage of the design process, if a method shows failure or is experimentally unachievable, the design loop must restart.

\section{Electromagnetic optimization}

The design parameters and characteristics of BETA in Table I are the results of the electromagnetic optimization. The optimization technique utilizes a genetic algorithm to minimize the ohmic heating power produced in the conducting arcs of a resistive Bitter magnet. This precursor design method can be used for either nested, split, or solenoid designs. ${ }^{2}$ The optimization calculates the theoretical resistance, voltage, and power of the magnet for numerous user-defined constants
TABLE I. Inputs and outputs of BETA's design specifications evaluated with the electromagnetic optimization. The design specifications are preliminary and help to advance the design of the magnet. Voltages, resistance, and power are calculated for the optimal operating current of $1175 \mathrm{~A}$ and the average conductor temperature constant of $44.5^{\circ} \mathrm{C}$. Please see nomenclature for parameter definitions.

\begin{tabular}{llcc}
\hline \hline Specifications & Parameter type & Value & Units \\
\hline$B$ & Input & 1.03 & $\mathrm{~T}$ \\
$r_{1}$ & Input & 0.02 & $\mathrm{~m}$ \\
$t$ & Input & 0.0005 & $\mathrm{~m}$ \\
$\lambda_{\text {Filling }}$ & Input & 0.8113 & Dimensionless \\
$T_{\text {avg }}$ & Input & 44.5 & ${ }^{\circ} \mathrm{C}$ \\
$r_{2}$ & Output & 0.0698566 & $\mathrm{~m}$ \\
$N_{\mathrm{c}}$ & Output & 81 & Dimensionless \\
$N$ & Output & 77.625 & Dimensionless \\
$l$ & Output & 0.0805 & $\mathrm{~m}$ \\
$V_{0}$ & Output & 0.268 & $\mathrm{~V}$ \\
$V_{t}$ & Output & 20.773 & $\mathrm{~V}$ \\
$L$ & Output & 196.86 & $\mu \mathrm{H}$ \\
$I$ & Output & 1175 & $\mathrm{~A} \mathrm{DC}$ \\
$R$ & Output & 17.679 & $\mathrm{~m} \Omega$ \\
$P$ & Output & 24408.38 & $\mathrm{~W}$ \\
\hline \hline
\end{tabular}

and constraints. A single solenoid configuration for ALPHA was selected, and therefore the same configuration is used for BETA. Two important constants that define the magnet's design are the prescribed averaged conductor temperature, $T_{\text {avg }}$, and the filling factor, $\lambda_{\text {Filling }}$. BETA's averaged conductor temperature is calculated at $44.5^{\circ} \mathrm{C}$, and its filling factor equals $81.13 \%$.

The filling factor, related to the packing, space, and density factor, is used by designers to describe the cooling hole density in Bitter magnets. ${ }^{8-10}$ Our magnet designs define the filling factor as the ratio of Bitter arc volume with machined geometry (i.e., arc cutout, cooling, and tie rod holes), $V_{\text {Arc }}$, to the volume of an annulus without machined geometry, $V_{\text {Annulus }}$,

$$
\lambda_{\text {Filling }}=\frac{V_{\text {Arc }}}{V_{\text {Annulus }}} .
$$

Analytical magnet properties in Tables I and II are calculated using the filling factor of BETA after water jet machining. Elongated cooling and tie rod holes on the conductors were offset by $0.5 \mathrm{~mm}$ to account for the thickness of the water jet cutter's stream. The jet cuts along the outside of the cooling hole's outline, resulting in $2.5 \mathrm{~mm}$ radially thick cooling holes and a filling factor of $84.71 \%$. Stacked conductors also overlap by $15^{\circ}$, which decreases the filling factor to $81.13 \%$. The degree of conductor overlap is set by the insulator's arc cutout.

The coil's resistance varies with the conductor's temperature. A conductor's resistivity is a function of temperature given by

$$
\rho_{\mathrm{avg}}=\rho_{0}\left[1+\alpha\left(T_{\mathrm{avg}}-T_{0}\right)\right],
$$

where $\rho_{0}$ is the resistivity at reference temperature $T_{0}$ and $\alpha$ is the temperature coefficient of resistivity. The resistivity is then used to calculate the magnet's coil resistance,

$$
R=\frac{2 \pi N \rho_{\mathrm{avg}}}{\lambda_{\text {Filling }} t \log \left(\frac{r_{2}}{r_{1}}\right)},
$$


TABLE II. Outputs from the thermal design for BETA based on the parameters listed in Table I. There is a total of five different cooling channel designs which are numbered radially outward (CC\#). Each cooling channel has a constant radial thickness of $2.5 \mathrm{~mm}$ and an elongated span angle of $4.5^{\circ}$. The thermal parameters are calculated with the conditions of $5{ }^{\circ} \mathrm{C}$ pre-chilled water and a centrifugal pump supplying $2.16 \mathrm{~kg} / \mathrm{s}$. The FEA averaged cooling channel wall temperatures are displayed here to compare with the analytical results.

\begin{tabular}{llccccc}
\hline \hline Parameter & $\mathrm{CC} 1$ & $\mathrm{CC} 2$ & $\mathrm{CC} 3$ & $\mathrm{CC} 4$ & $\mathrm{CC} 5$ & Units \\
\hline$r_{p}$ & 0.0243 & 0.0322 & 0.0401 & 0.0504 & 0.0645 & $\mathrm{~m}$ \\
$A$ & 9.68 & 11.23 & 12.78 & 14.80 & 17.57 & $\mathrm{~mm}^{2}$ \\
$v_{p}$ & 1.623 & 1.176 & 1.792 & 1.873 & 1.959 & $\mathrm{~m} / \mathrm{s}$ \\
$\dot{m}$ & 1.57 & 1.93 & 2.29 & 2.77 & 3.44 & $10^{-2} \mathrm{~kg} / \mathrm{s}$ \\
$h$ & 7191.0 & 7448.3 & 7653.7 & 7866.7 & 8089.4 & $\mathrm{~W} /\left(\mathrm{m}^{2} \mathrm{~K}\right)$ \\
$T_{\text {outlet }}$ & 11.51 & 8.76 & 7.92 & 7.62 & 6.72 & ${ }^{\circ} \mathrm{C}$ \\
$T_{\text {w }}$ & 53.74 & 48.50 & 44.15 & 40.02 & 36.10 & ${ }^{\circ} \mathrm{C}$ \\
$T_{\text {w, (FEA) }}$ & 57.14 & 52.10 & 47.91 & 44.24 & 39.94 & ${ }^{\circ} \mathrm{C}$ \\
\hline \hline
\end{tabular}

where $N$ is the number of magnetic turns, $t$ is the conductor's thickness, $r_{1}$ and $r_{2}$ are the inner and outer radius of the Bitter arcs, respectively. The contact resistance due to the conductors' overlap is neglected, and therefore BETA's total magnetic turns will equal the total number of conductors in the coil, $N_{\mathrm{c}}=81$, subtracted by 3.375 turns due to overlapping. The electromagnetic properties in Table I are calculated with $N=77.625$. Using resistance and acquired current, the user can obtain the voltage drop over the magnet core as well as the electrical power consumed. These values advance to the thermal design where they are used to radially place the cooling channels on the magnet's core.

\section{Thermal design}

There are 90 cooling holes on BETA's arc design which are separated into five cooling rings each consisting of 18 cooling holes. Cooling holes within the same cooling ring are similar in geometrical design. The geometrical design of the cooling holes differs only between cooling rings, and therefore only five cooling hole designs exist on the conductor. The thermal characteristics of each cooling hole design can be seen in Table II. These parameters are found by using both geometry and the electrical characteristics from Table I.

BETA's thermal design began with the user defining the total number of cooling rings, which were initially placed radially along a Bitter arc using a hyperbolic tangent stretching function proposed in 1983 by Vinokur, ${ }^{11}$

$$
S(\zeta)=\mathrm{d} r\left[1+\frac{\tanh (b(\zeta-1))}{\tanh (b)}\right]
$$

where $0 \leq \zeta \leq 1$ is the intermediate parametric space, $S$ is the physical space, $\mathrm{d} r$ is the total radial extent of the Bitter arc, and $0 \leq b$ is the tightness factor. The parametric space is divided by the total number of cooling rings. This provides parametric coordinates to output the physical space of the cooling holes' centered radial positions. Increasing the tightness factor will densely pack the cooling holes toward the inner radii of the Bitter arc, while a tightness factor of 0 will evenly place all cooling holes.

The cooling holes' have a constant radial thickness which is calculated as a function of both their radial positions and the filling factor. After defining the radial thickness, mass flow rates and velocities are determined through a parallel pipe resistance analysis. Each individual cooling channel is considered a pipe with the characteristic Borda-Carnot head loss,

$$
\Delta P=\frac{K \dot{m}^{2}}{2 A^{2} \rho_{\mathrm{w}}},
$$

where $K$ is the resistance coefficient, $\dot{m}$ is the mass flow rate, $A$ is the cross-sectional area of the cooling hole, and $\rho_{\mathrm{w}}$ is the density of water. Assuming a constant head loss for all cooling channels in the magnet, the mass flow rates are found for each cooling channel. The mass flow rates are converted to velocities and inserted into the Dittus-Boelter equation to calculate the heat transfer coefficient for each individual cooling channel's wall. ${ }^{12}$

The conducting Bitter arc is broken up into polar rectangles with each segment consisting of a cooling hole. The total heat generated in each element is calculated and then used in a system of cylindrical thermal resistance circuits to predict the wall temperature of each cooling hole. Convection and the radial conduction between each polar rectangle element are considered. Wall temperatures, $T_{\mathrm{w}}$, are solved in a linear system of equations as a function of electrical operating current. The wall temperatures of the cooling holes are averaged to produce $T_{\mathrm{avg}}$, which is used for approximating the average temperature of the conductor. After the initial cooling hole placement and wall temperature calculations, a while loop was used to reposition the cooling holes until the temperature, $T_{\text {avg }}$, is within a tolerance of $10^{-6}$ from the user-defined temperature in the electromagnetic optimization. BETA's cooling hole positions produce a linear temperature distribution along the conductor.

\section{B. Finite element analysis (FEA)}

The magnet core is modeled in soliDWorKs and uploaded to ANSYS wORKBENCH, where the magnetic field profiles are evaluated within $0.1 \%$ error in a magnetostatic analysis using ANSYS maxwell. A contour plot of the 2D magnetic field of BETA can be seen in Fig. 1, where the model was applied with a current-turn excitation. The MAXwELL FEA results are compared against analytical values and then loaded into other ANSYS modules. 


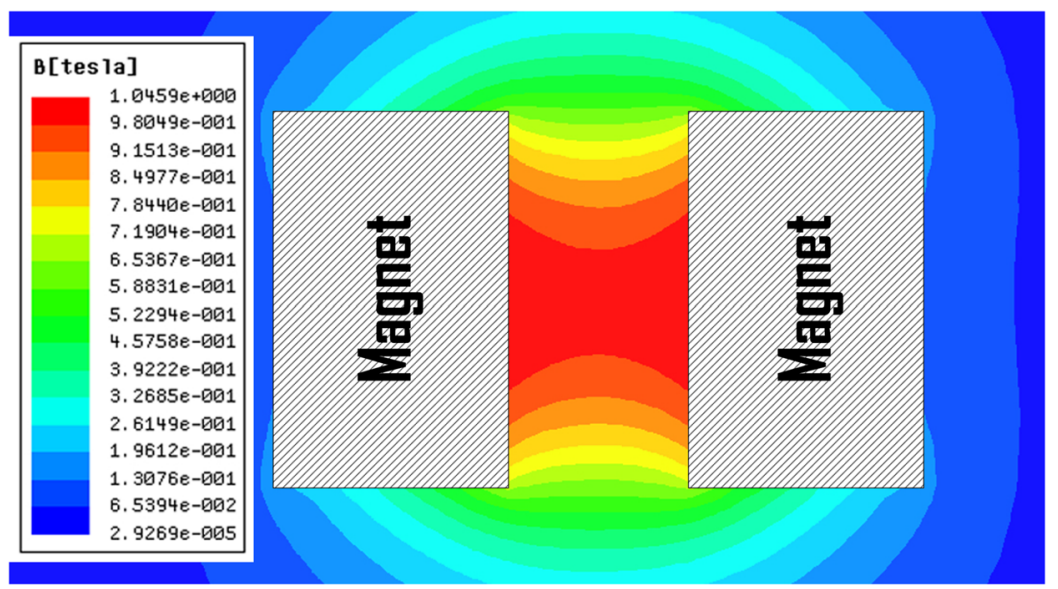

FIG. 1. The magnetic field magnitude 2D contour plot along BETA's XZ plane for 1175 A.
The model is then moved into ANSYS THERMAL-ELECTRIC to complete an FEA analysis of conductor's temperature profile, current density, and volumetric joule heating for verification of the analytical design. The cross section of BETA's model is applied with voltage boundary conditions using the voltage drop across a single conductor, $\mathrm{V}_{0}$, in Table $\mathrm{I}$. Convective boundary conditions are applied to the walls of each cooling hole using the heat transfer coefficients listed in Table II. The FEA averaged cooling channel wall temperatures, $T_{\mathrm{w},(\mathrm{FEA})}$, are obtained by averaging all element nodal wall temperatures from each cooling hole within each specified cooling channel ring. Averaged FEA cooling hole wall temperatures are presented in Table II and can be compared with the analytical cooling hole wall temperatures, $T_{\mathrm{w}}$, for each cooling hole design. The temperature profile of the BETA's conducting arc is presented in Fig. 2(a). To produce the average steady state temperature of the conductor, $T_{\mathrm{avg}(\mathrm{FEA})}=46.61^{\circ} \mathrm{C}$, all element nodal temperatures in the FEA model are averaged. The average conductor temperature, $T_{\mathrm{avg}}=44.5^{\circ} \mathrm{C}$, is approximated as the average of the analytical cooling hole wall temperatures. In this case, the percent error between the FEA and analytical average conductor temperatures is $4.53 \%$. The FEA results vs analytical current density and volumetric joule heating are plotted in Fig. 2(b) along the black-dashed line in Fig. 2(a). The FEA magnitudes, both current density and volumetric joule heating, decrease between cooling holes along this radial path due to both the modeled geometry and the increased conductor temperature distribution.

The mechanical characteristics of the coil are considered for both the magnetic field forces and thermal operating
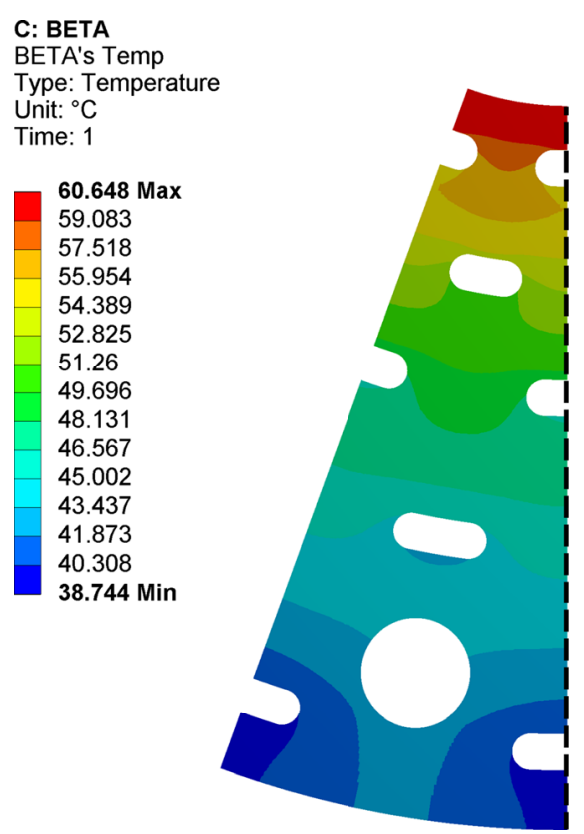

(a)

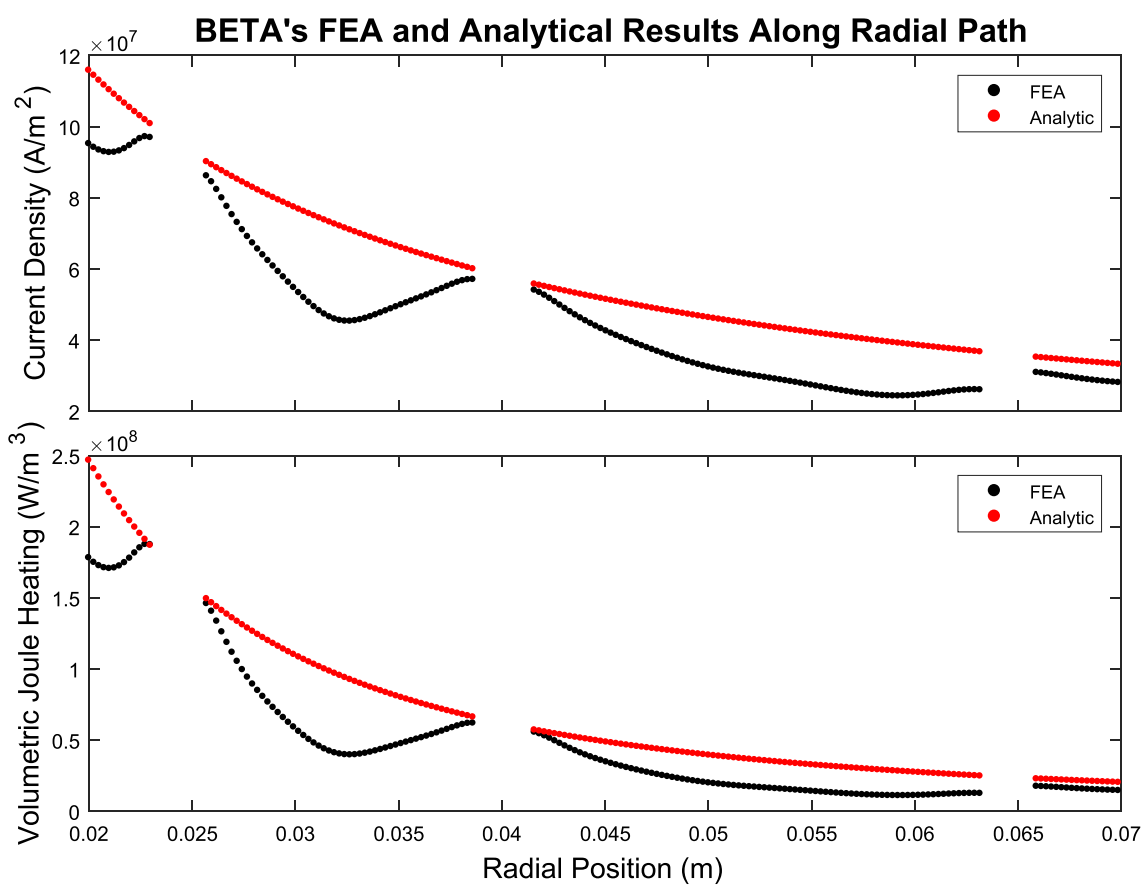

(b)

FIG. 2. Temperature profile on the Bitter conductor arc with boundary conditions provided from Tables I and II is displayed in (a). The average conductor temperature is $T_{\text {avg,(FEA) }}=46.61{ }^{\circ} \mathrm{C}$. In (b), current density and volumetric joule heating are calculated for both the FEA and the analytical methods along the black-dashed line in (a). 
TABLE III. The mechanical stress design FEA outputs for BETA are displayed in this table. These are design parameters which are calculated through ANSYS WORKBENCH with the linked modules MAXWELL, THERMAL-ELECTRIC, and STATIC-STRUCTURAL.

\begin{tabular}{lcc}
\hline \hline Parameter & Value & Units \\
\hline$F_{\text {body,max }}$ & 6.415 & $10^{7} \mathrm{~N} / \mathrm{m}^{3}$ \\
$x_{\text {total,max }}$ & 4.913 & $10^{-5} \mathrm{~m}$ \\
$x_{\text {total,avg }}$ & 3.437 & $10^{-5} \mathrm{~m}$ \\
$\sigma_{v, \text { max }}$ & 1.588 & $10^{6} \mathrm{~Pa}$ \\
$\sigma_{v, \text { avg }}$ & 3.023 & $10^{5} \mathrm{~Pa}$ \\
$\epsilon_{\text {eq,max }}$ & 1.444 & $10^{-5} \mathrm{~m} / \mathrm{m}$ \\
$\epsilon_{\text {eq,avg }}$ & 2.750 & $10^{-6} \mathrm{~m} / \mathrm{m}$ \\
FOS & 158 & Dimensionless \\
\hline \hline
\end{tabular}

temperatures. The mechanical FEA results of BETA are shown in Table III. The magnetic forces from MAXwELL and temperatures from THERMAL-ELECTRIC are applied as boundary conditions in ANSYS STATIC-STRUCTURAL. The mechanical analysis also requires frictionless support boundary conditions applied to the cyclic sides of the model. In this module, the total deformations, stresses, and strains can be assessed. The total deformations of BETA at operating current and temperature can be seen in Fig. 3. Here, the maximum deformation shows $49.13 \mu \mathrm{m}$ at the outer radius of the conductor. The yield stress of the copper, $250.3 \mathrm{MPa}$, divided by the coil's maximum stress, $1.588 \mathrm{MPa}$, results in a FOS of 158. Analytical methods are currently being derived to make the magnetic design process completely analytic and validated with

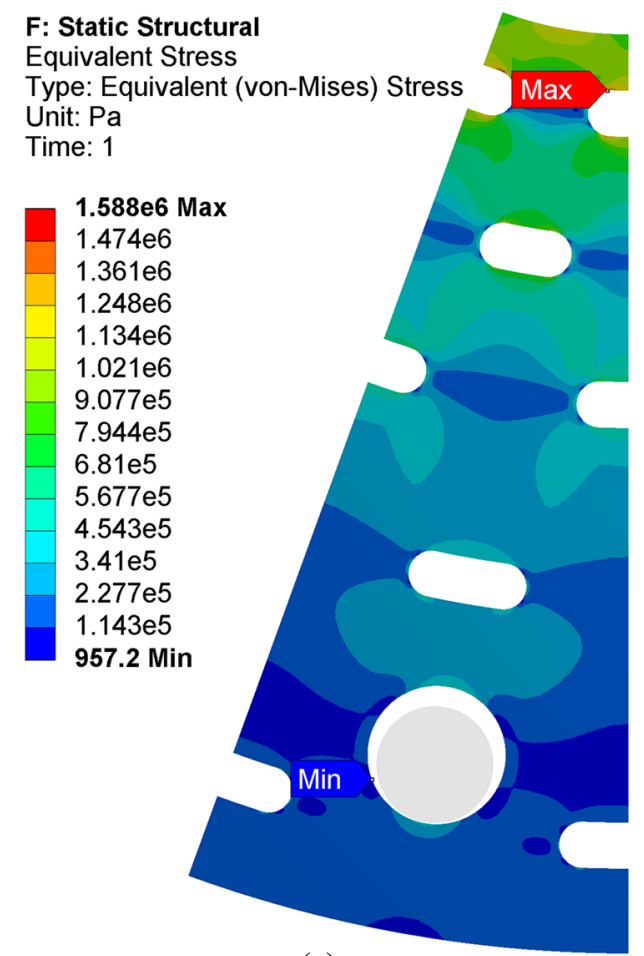

(a) measured quantities from BETA to reduce reliance on FEA for the design process.

\section{MAGNET CORE}

The magnet core, displayed in Fig. 4, is the foundation of the entire system, and all other subsystems are driven by its design. The core is assembled with a straightforward continuous stacking method that involves alternating Bitter conducting and insulating arcs. In this approach, each Bitter conducting arc is considered a full magnetic turn. The conductor and insulator have the same thickness to prevent radial gaps in the coil. Once the coil is stacked, helix starters are placed on both sides of the coil to create a flat surface. Aluminum clamping annuli are then bolted on both ends of the coil over the helix starters. Insulating clamping annuli are placed and then insulated 304 stainless steel tie rods are inserted through the coil and torqued to $11.3 \mathrm{~N}-\mathrm{m}$. The force allows for good electrical contact between the stacked Bitter conducting arcs. The clamping annuli distribute the compression uniformly and are electrically connected with the coil. Aluminum clamping rings are then placed on top of the insulating clamping annuli, allowing for insulated connection to the magnet's vessel. They also seal and restrict water flow for the space between the clamping annuli and vessel's wall. Once the magnet's core is fully assembled, threaded standoffs are screwed into a threaded through hole on both clamping annuli. The torqued standoffs make contact with the outermost Bitter conducting arcs of the coil. An aluminum bus bar connects the standoff to $4 / 0$ American Wire Gauge (AWG) cable that is fed through

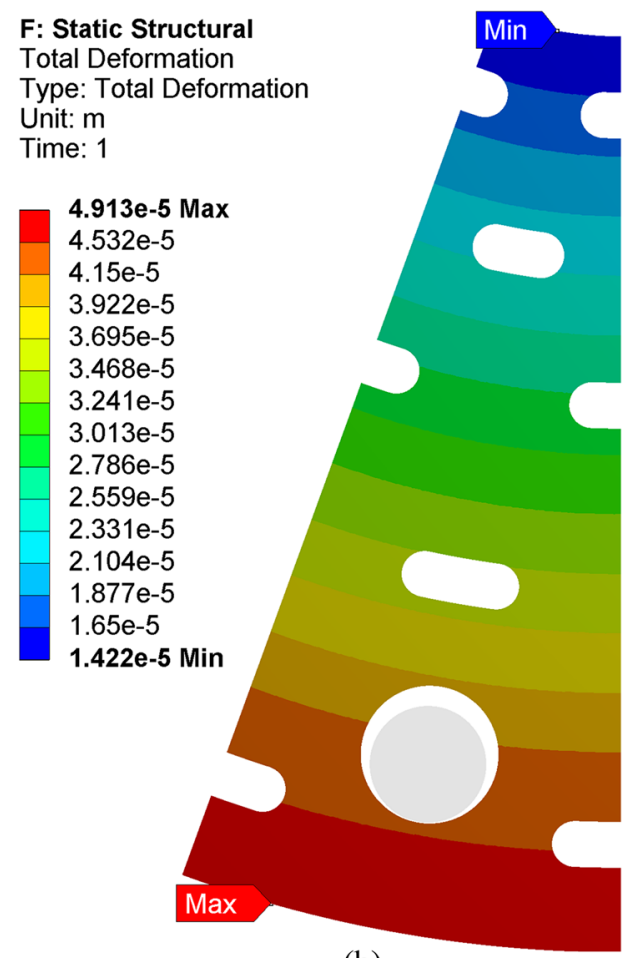

(b)

FIG. 3. The equivalent stress (a) and total deformations (b) are displayed here for BETA's centered conducting arc under operating current 1175 A DC, temperature $T_{\text {avg(FEA) }}=46.61{ }^{\circ} \mathrm{C}$, and Lorentz forces. 


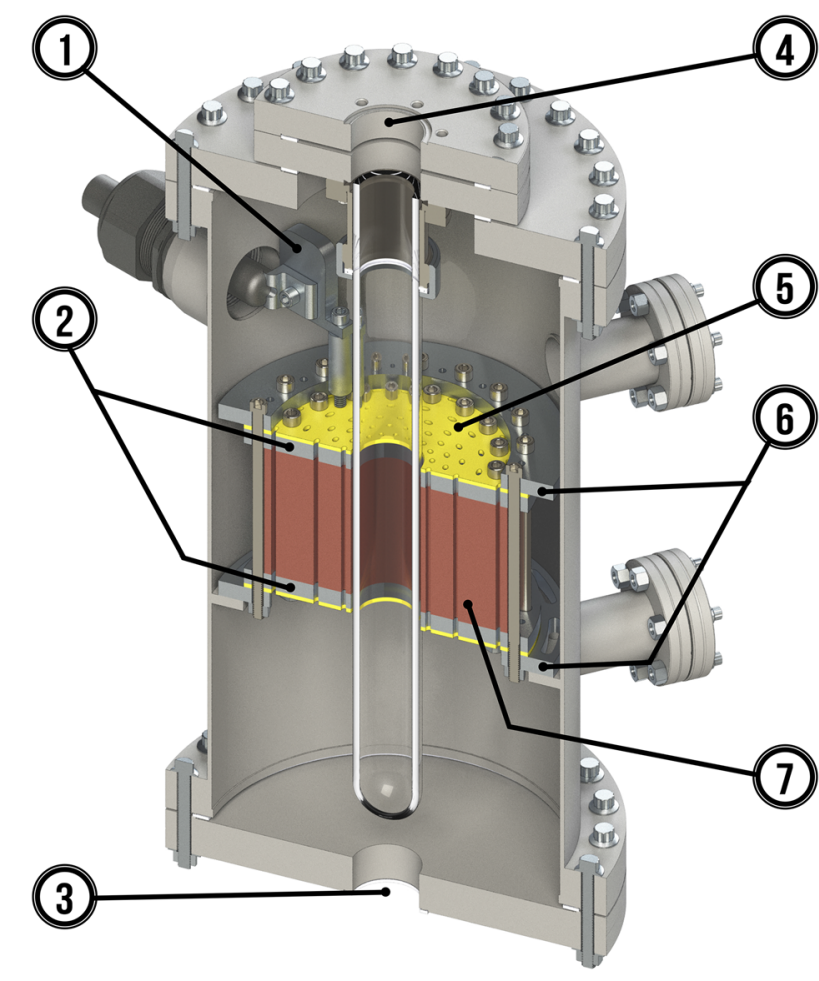

FIG. 4. BETA's magnet assembly includes: electrical connection to the core (1), clamping annuli (2), vessel's water outlet (3), 3-cm vacuum compatible borosilicate bore (4), insulating clamping annuli (5), clamping rings (6), and the stacked Bitter coil (7).

water-tight core grips on the vessel and into the electrical system. Magnet polarity can be switched with the current direction through the magnet assembly by switching the cable leads on the electrical system.

\section{A. Bitter conducting arc}

The conductor is made from $0.5-\mathrm{mm}$ thick Electrolytic Tough Pitch (ETP) copper C101-H02. The design has 90 cooling holes, 18 (7.5-mm diameter) tie rod holes, and a $5^{\circ}$ arc cutout for stacking the conductor into a helix. Conventionally, Bitter arcs are manufactured by a stamping process where a die must be made for the cooling hole design. ${ }^{13}$ Instead, the copper arcs are machined with an OMAX 2652 waterjet cutter. Water jetting leaves a significant blowout burr on the opposite side of the metal, so a magnetic deburrer was made specifically to process the arcs. Three 1-T permanent magnets are rotated below a plastic canister filled with deionized water, stainless steel rods, and brass cleaner. When the magnets rotate, the rods act as an abrasive to the copper arcs, significantly reducing the burrs that could cause electrical shorts between arcs.

\section{B. Bitter insulating arc}

The insulator mirrors the Bitter conducting arc's design, with the exception of a larger arc cutout angle of $15^{\circ}$ compared to $5^{\circ}$ for the conductor arc. The insulator isolates neighboring conductors and accommodates a $15^{\circ}$ conductor overlap, establishing electrical connection between stacked conductors and forming the helical current path of the coil. Bitter insulating arcs are made from 0.5-mm thick G10-FR4 and are inserted inbetween the Bitter conducting arcs. Attempts were made to cut these arcs out on the waterjet cutter; however, these attempts failed because G10 is a laminate material. The high-pressure jet separates layers during the initial puncture, and water propagates between layers causing material bulging. We determined that laser cutting is the best manufacturing method for the insulating Bitter arcs. A $150-\mathrm{W} \mathrm{CO}_{2}$ laser from UNIVERSAL LASER sYSTEMS was used to cut each arc.

\section{Coil helix starters}

The helix starters are laser-cut Bitter arc sections from $125-\mu \mathrm{m}$ thick Mylar sheets. An assembled helix starter is placed on the top and bottom of the fully stacked coil. The starters fill the gap between the flat surface of the aluminum clamping annuli and the helix profile of the coil. BETA's helix starters each consist of five Mylar pieces. They are consecutively stacked such that the starter grows in thickness from $125 \mu \mathrm{m}$ to $0.5 \mathrm{~mm}$, the thickness of a single Bitter arc. A helix starter can be seen in Fig. 5. Contact resistance between conducting arcs improves through the entire coil with the use of helix starters.

\section{Bitter clamping annuli}

The clamping annuli help secure and compress the coil. One of the largest design challenges is preventing a short circuit between the two clamping annuli through the tie rods. To avoid electrical shorts between Bitter conductors inside the coil, the tie rods are insulated with polyolefin tubing. We had initially designed and machined the clamping annuli

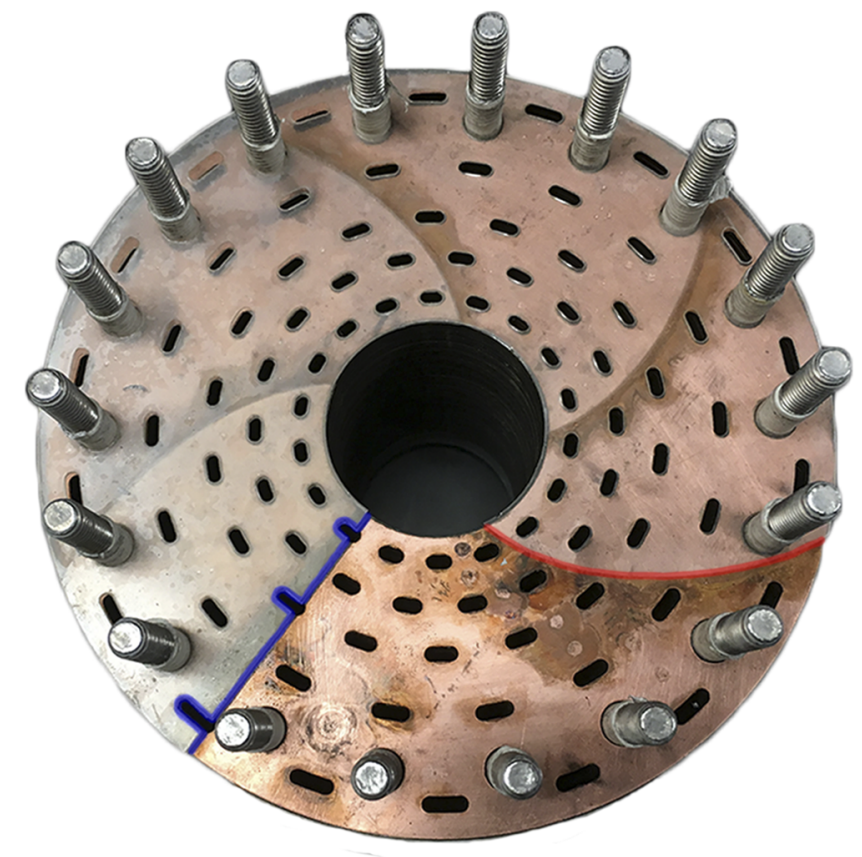

FIG. 5. The helix starter is made from thin consecutively stacked sheets of Mylar. Shown here is a fully stacked helix starter on the bottom Bitter arc conductor of the magnet core. The starter grows in thickness clockwise from the red line to blue line. They are made with similar cooling hole patterns so that flow through cooling channels is not obstructed. 
using high-density polyethylene (HDPE) to prevent electrical shorts. When clamped down, the tie rods rest on the HDPE to prevent any shorts. However, the compression force needed for good electrical connection surpassed the yield strength of HDPE, and the tie rods would depress into the material and cause deformation. Improvements were focused on making the clamping annuli out of metal to avoid this issue. In the final design of BETA, the clamping annuli are composed of 9.525-mm thick aluminum and are conducting current to the outermost Bitter conducting arc. The annuli have oval shaped cooling holes to ensure adequate water flow when the coil is under stress. The tie rods are insulated by stacking five similarly designed clamping annuli made of $0.5-\mathrm{mm}$ thick G10-FR4 on top of the aluminum. The G10-FR4 acts as a washer for the tie rods to rest on and isolates any possible electrical short. The G10-FR4 has a strong compression strength of $413.7 \mathrm{MPa}$ and a dielectric strength of $\sim 4.5 \times 10^{5} \mathrm{~V} / \mathrm{m}$.

\section{MAGNET VESSEL}

The magnet's vessel was fabricated from a repurposed 304 stainless steel vacuum nipple that is $0.2032 \mathrm{~m}$ in diameter. A total of seven ports were welded onto this vessel: two for electrical access, one as a water inlet, one for thermocouple access, and three as viewports. A ring was welded inside the vessel to support the magnet core. The bottom of the vessel has a conflat flange that is used as a water outlet. The top of the vessel is made of another conflat flange. A custom borosilicate bore and magnetic probe support are bolted to the flange. The bore is $3 \mathrm{~cm}$ in diameter and $36 \mathrm{~cm}$ in depth. The magnetic probe support allows for three axis movements of a three-channel $\left(B_{\mathrm{x}}, B_{\mathrm{y}}, B_{\mathrm{z}}\right)$ Hall probe (MMZ-2508-UH-06), measured with a LAKE SHORE 460 gaussmeter inside the bore. The support allows fine tuning of the probe's position to find the center of the bore. The vessel and all surrounding support structures are made from nonmagnetic materials.

\section{WATER DELIVERY AND COOLING SYSTEM}

The electrical power produced at the core is dissipated by a closed-loop cooling system, illustrated in Fig. 6. Water is first deionized to a resistivity of $1-\mathrm{M} \Omega \mathrm{cm}$ from the building water supply and added into the closed loop system through the globe valve. Once the system has been filled to the desired water capacity, it is turned on and circulates for about an hour removing any unwanted trapped air pockets. To protect against cavitation and oxygenation, multiple air eliminators (AE), active element, are placed throughout the system. The system operates as follows: deionized water is pumped from a 1041-1 intermediate bulk container (IBC) and a y-type strainer through a $2.54-\mathrm{cm}$ diameter schedule-one PVC tubing at $2.16 \mathrm{~kg} / \mathrm{s}$ using a centrifugal pump (Cascade 1/8-36) from PERForman CEPRo. The pump moves the water though the coils of a heat exchanger in a 2-ton water chiller (MT-1-WCV) from AQUA LOGIC. A flow switch, F, activates the water chiller. The water is chilled to $5^{\circ} \mathrm{C}$ and then moves to a 3 -way valve, where water can flow through the magnet or is diverted back to the ICB tank. This allows the magnet section to be closed off, drained, and disassembled if necessary. During operation, water is diverted

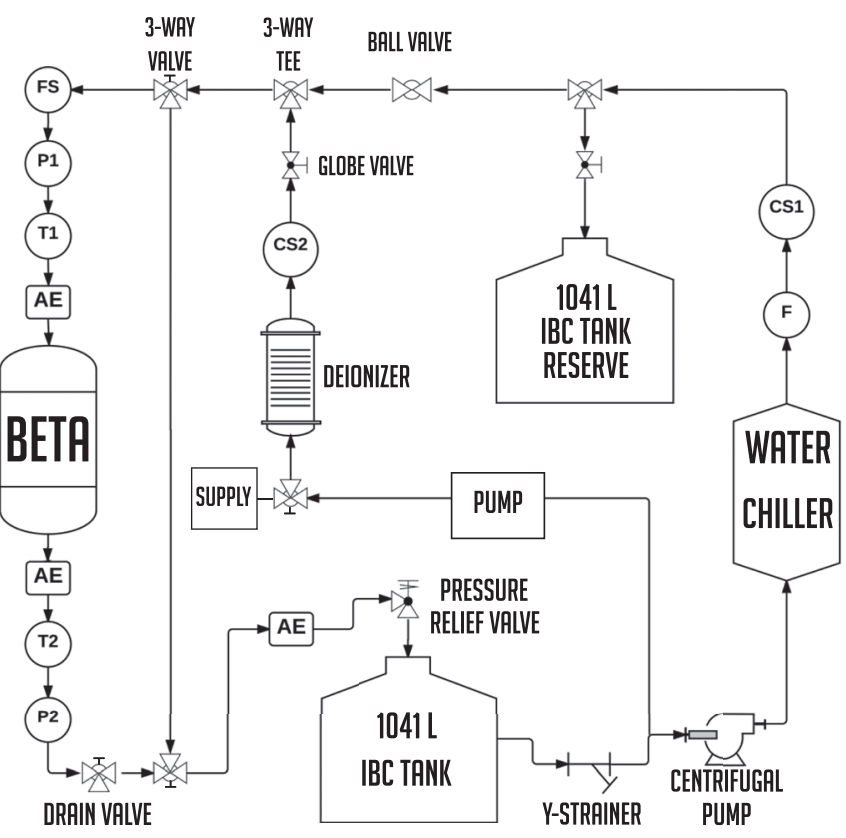

FIG. 6. BETA's closed loop cooling system.

to the inlet of the magnet vessel, where the mass flow rate is measured with a F-300 pitot tube from BLUE-WHITE. A magnetic flow sensor, FS, is attached to the pitot tube to detect flow within 1.85 and $3.11 \mathrm{~kg} / \mathrm{s}$. The water's temperature is measured with a PT100 resistance temperature detector (RTD), at $\mathrm{T} 1$ and $\mathrm{T} 2$, and the pressure is measured with a transducer at P1 and P2. The sensors are connected to a six-pipe manifold where more data acquisition (DAQ) probes can be added. Water moves into the vessel and is forced through the cooling channels of the core by using a custom-made gasket around the top clamping ring.

Water must be deionized periodically to ensure resistance is orders of magnitude larger than the magnet so that the water does not create an electrical short. The conductivity of water is indicated with $1-\mathrm{M} \Omega \mathrm{cm}$ sensor lights at CS1 and CS2. If the sensor goes above $1-\mathrm{M} \Omega \mathrm{cm}$, the light will turn red, and the water must again be deionized. For routine deionization, water is extracted with a small pump, diverted through the deionizer, and inserted back into the system.

The averaged frictional pressure drop during operation measured with the inlet and outlet pressure transducers is $7.72 \mathrm{kPa}$. Analytical calculations show a pressure drop over the magnet core to be about $9.69 \mathrm{kPa}$. This is calculated during the thermal design stage using the parallel pipe analysis with an approximated 2-mm effective roughness height. ${ }^{14}$ Experiments are planned to determine the exact roughness factor of aligned cooling channels manufactured at DPL. Experimental results will be used for acquiring water pumps with correct specifications for ALPHA.

Deionized water is corrosive to the magnet core. At the end of six months, a resistance, across the magnet assembly (electrically disconnected) of $15.9 \mathrm{~m} \Omega$ was measured at $5{ }^{\circ} \mathrm{C}$ using an ехтесн $380560 \mathrm{~m} \Omega \mathrm{m}$. The core was removed from the vessel and cleaned. Galvanic corrosion coupled with electrolysis and deionized water pitted the aluminum clamping assembly, but left the copper Bitter arcs unaffected. 
The magnet assembly was refurbished to the resistance of $15.62 \mathrm{~m} \Omega$, measured again at $5{ }^{\circ} \mathrm{C}$ with the milliohm meter. Nitrogen bubbling will be implemented in the future to remove dissolved oxygen from the water.

\section{ELECTRICAL SYSTEM}

About $1175 \mathrm{~A} \mathrm{DC}$ is needed to reach magnetic fields of $1 \mathrm{~T}$ with BETA. Commercial electrical systems can be purchased for the maximum current of BETA; however, such systems are not available for ALPHA. Therefore, to scale to the 10-T system, a custom electrical circuit has been built. The primary function of the electrical system is to break the current supply to the magnet.

\section{A. Power supply}

The shot duration of ALPHA is designed to be at least $10 \mathrm{~s}$ and, therefore, limits the choice of devices to supply the power. Bitter magnets that have employed capacitor banks typically have pulse durations on the order of milliseconds to microseconds. ${ }^{15}$ We chose a bank of six absorbant glass mat (AGM) deep discharge batteries, 12FLX540 13.6-13.8 V, from FIAMM. There are two strings (parallel connections) in the bank, each consisting of three batteries connected in series with aluminum bus bars providing a maximum voltage of $41.4 \mathrm{~V}$. All bus bar connections are torqued down to $11.3 \mathrm{~N}-\mathrm{m}$ and applied with oxide inhibiting electrical joint compound (EJC). Each string can deliver $\sim 587.5 \mathrm{~A}$ for at least $10 \mathrm{~s}$. These batteries can typically handle 3787 A short circuit current with a 150 Ah rating. The magnet can be on for the duration of $7.7 \mathrm{~min}$ for complete battery drain; however, because of decaying current and magnetic field, shots are typically kept under $30 \mathrm{~s}$. The batteries are recharged to their full potential after 30 shots with a commercial battery charger, SE-1072, from scHUMACHER.
Diodes are attached to the positive leads on each battery string to prevent reverse current in the bank.

The battery bank is connected to a Gerapid 4207 from GE. This is a large DC circuit breaker that can conduct $4200 \mathrm{~A}$ DC continuously and is an auxiliary switch for the solid-state breaker (SSB). The Gerapid switches the current off if the primary SSB fails. The breaker is powered by a custom external 120 V DC power supply from ABSOPULSE.

\section{B. Solid-state breaker (SSB)}

High DC current switching is a problem because the waveform is constant and does not cross zero like alternating current. Therefore, a silicon-controlled rectifier (SCR), also known as a thyristor, circuit breaker method has been developed for BETA and future magnet systems. The SCR is forced commutated with an LC branch that consists of an electrolytic polarized capacitor and a shielded wire-wound inductor. The branch is triggered by parallel insulated gate bipolar transistors (IGBTs). IGBTs are subject to damage from high voltage spikes and are only used as triggers for the SCRs. IGBTs were configured in parallel to lower the maximum current specifications for readily available IGBTs. An SCR was selected to conduct the operating current due to its robustness and reliability. ${ }^{16}$ This circuit is based on the original thyristor circuit breaker concept and the thyristor circuit breaker for the pulsed 40-T magnet at Wuhan National Magnetic Field Center (WNMFC). ${ }^{17,18}$ Key features that make BETA's circuit original are the use of AGM batteries, the elimination of a commutation film capacitor bank, SCR and IGBT triggering from the positive rail of the battery bank (eliminating the need of external power supplies), and a variable water-cooled stainless steel resistor. This circuit reduces the cost by two orders of magnitude from mechanical relays. The system has been tested for robustness and stability of operation over many

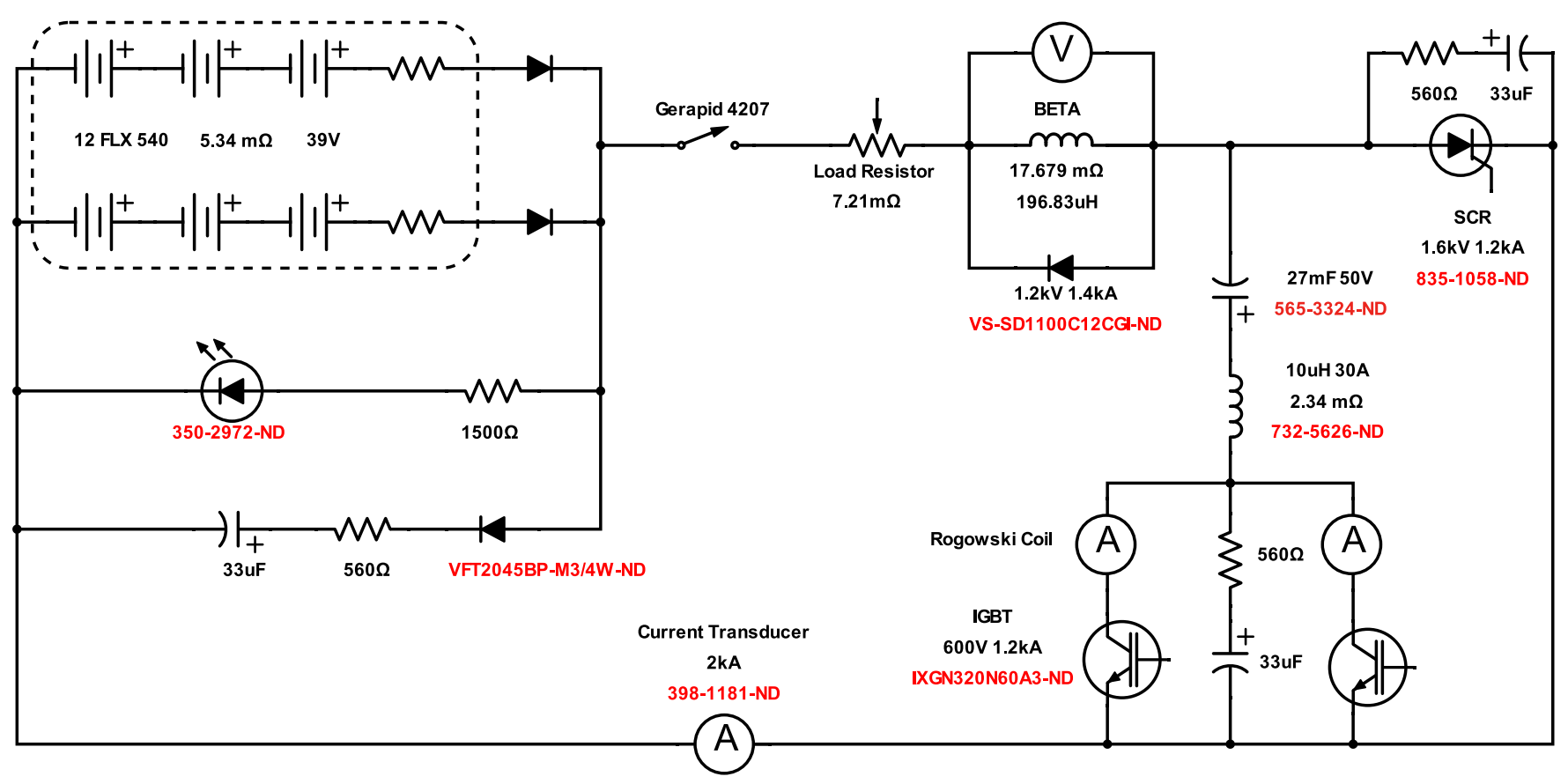

FIG. 7. BETA's SSB electrical subsystem circuit diagram with part numbers in red. 
cycles. The circuit diagram can be seen in Fig. 7 with all part numbers listed for reference.

To initiate the system, a variable water-cooled stainlesssteel resistor is set at a prescribed resistance to dial in the magnet's operating current, $I_{\mathrm{t}}$. For $1175 \mathrm{~A}$ and 1-T fields, the resistor is set at $5.85 \mathrm{~m} \Omega$ (measured at $16.3{ }^{\circ} \mathrm{C}$ with building water supply at $\sim 15^{\circ} \mathrm{C}$ ). The resistor will reach a steady state temperature and resistance of about $245^{\circ} \mathrm{C}$ and $7.21 \mathrm{~m} \Omega$, respectively, dissipating $9955 \mathrm{~W}$ of power under operating conditions.

The commutation capacitor is then pre-charged, using a BK PRECISION 9185 external power supply unit (PSU), to a voltage, $V_{\mathrm{c}(\mathrm{m})}$, large enough to force-commutate the conducting SCR. Capacitor voltages are determined by the following equation:

$$
V_{\mathrm{c}(\mathrm{m})}=I_{\mathrm{t}} R_{\mathrm{c}(\mathrm{m})}(\gamma-1),
$$

where $R_{\mathrm{c}(\mathrm{m})}$ is the measured resistance in the commutation current path,

$$
\begin{aligned}
R_{\mathrm{c}(\mathrm{m})}= & R_{\mathrm{Bank}}+R_{\mathrm{Load}}+R_{\mathrm{Magnet}} \cdots \\
& +R_{\mathrm{L}}+R_{\mathrm{IGBT}}+R_{\mathrm{Leads}},
\end{aligned}
$$

consisting of the internal resistance of the battery bank, $R_{\mathrm{Bank}}$ $=5.34 \mathrm{~m} \Omega$, variable load resistor, $R_{\mathrm{Load}}=7.21 \mathrm{~m} \Omega$, magnet, $R_{\text {Magnet }}=17.679 \mathrm{~m} \Omega$, inductor, $R_{\mathrm{L}}=2.34 \mathrm{~m} \Omega$, on-state resistance of the IGBTs, $R_{\mathrm{IGBT}}=0.5 \mathrm{~m} \Omega$, and the circuit resistance consisting of contacts, bus bars, and wires, $R_{\text {Leads }}=4.62 \mathrm{~m} \Omega$. The current factor, $\gamma$, was set to 1.6 in the circuit design. Once the capacitor is charged, the Gerapid breaker is closed, and the system is armed and ready for a shot. The magnet is turned on by first pulsing the gate of the SCR. Once the shot duration has concluded, the IGBT's gates are pulsed, allowing the capacitor to discharge into the circuit, dropping the current in the SCR below its specified holding current and applying a negative voltage across its cathode and anode for a duration longer than its specified turn-off time, $t_{\mathrm{q}}$. Once the current flow is broken, the Gerapid breaker is switched back to the open position, concluding the magnet shot.

\section{BETA'S DIAGNOSTICS AND SSB CONTROLLER}

Diagnostics and the SSB are controlled with ARDUINo Uno microcontrollers through a graphical user interface in MATLAB. From the cooling system sensors, the controller reads serial data consisting of temperature and pressure at the inlet and outlet of the vessel and flow switch boolean data. The temperatures from the RTD sensors are read with a dual MAX31865 PT-100 RTD to digital breakout board for ARDUINO from PLAY INGWITHFUSION. Data acquisition on the SSB consists of reading analog voltage of the magnet assembly with the Uno through a voltage divider. The operating current is measured with a closed loop Hall effect sensor powered by an external PSU at 19 V DC. The sensor outputs current from a secondary coil winding induced by BETA's operating current. The secondary current is measured by voltage drop over a $20 \Omega$ shunt resistor and to sense current magnitude in the magnet. Current in the commutation branch is measured with Rogowski coil integrator circuits. The signal output is measured with an oscilloscope to ensure that current is traveling equally through the parallel IGBTs. The magnetic field data are digitized with an ARDUINO using the analog output from the gaussmeter.

The primary function of the SSB controller is to send pulse width modulation (PWM) current pulses to the gates of both the SCR and IGBTs. The SSB controller circuit schematic can be seen in Fig. 8. MATLAB commands the aRduino to send a PWM to electromechanical relays for pulsing the SCR and

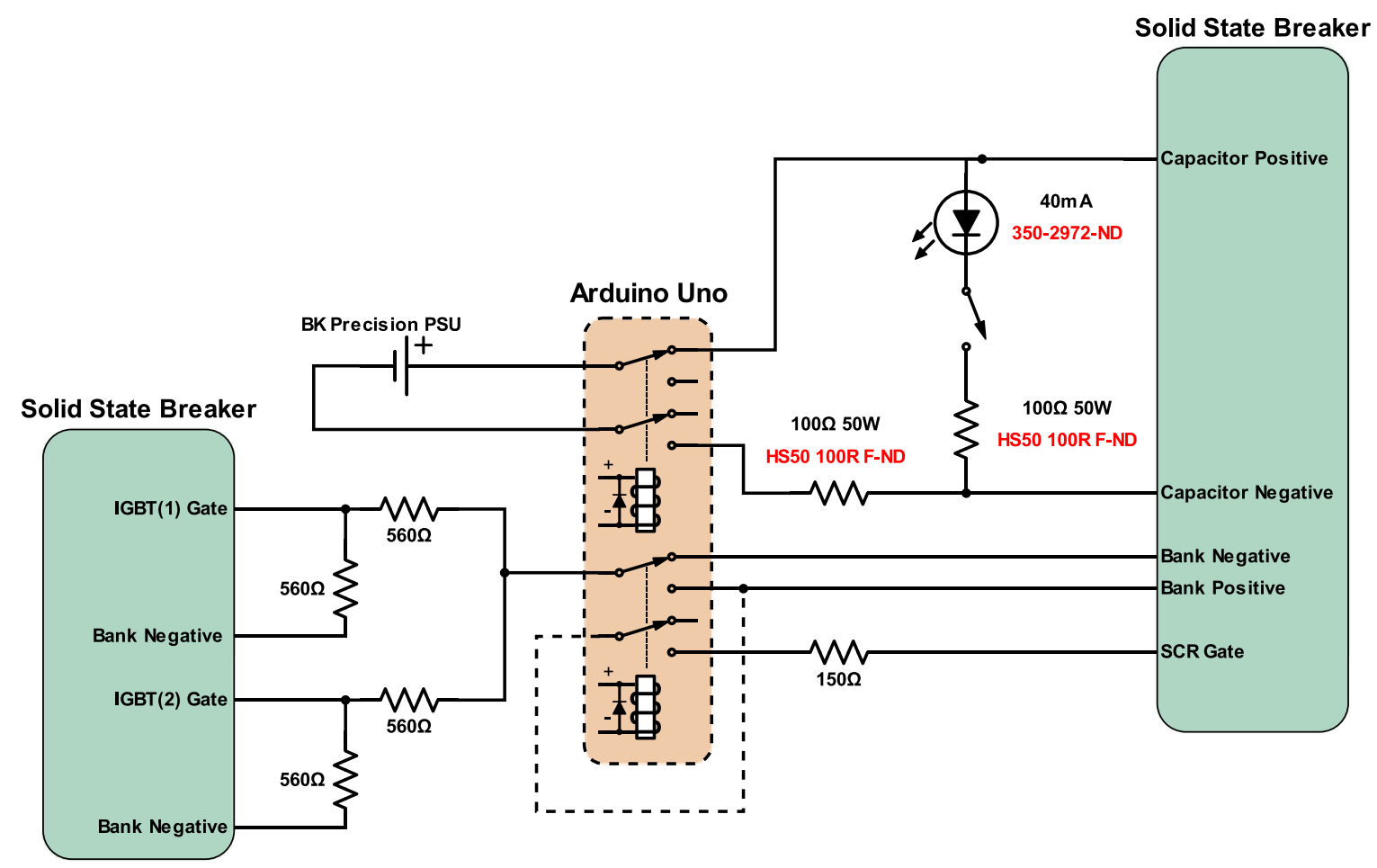

FIG. 8. The SSB controller circuit uses an ARDUINo Uno and a four channel dual pole relay for all functions. Part numbers in the figure are in red. 
IGBTs' gates. When pulsed, the relays close, connecting the positive of the battery bank to sized resistors and applying a specific voltage and current to the gates. The SCR's gate voltage and current is $4.18 \mathrm{~V}$ and $232 \mathrm{~mA}$, respectively. The IGBTs' gate voltage and current is $19.5 \mathrm{~V}$ and $34.8 \mathrm{~mA}$, respectively. To prevent running BETA without cooling, the controller will not pulse the SCR unless the flow switch reads true. The IGBTs will be pulsed automatically during operation if temperature or pressure at the vessel inlet or outlet exceed normal operating limits or water flow ceases in the system.

The secondary function of the SSB controller is commutation capacitor charging. Two relays are closed connecting an external PSU in series with the commutation capacitor and resistor for the duration of $10 R C$ time constants. The capacitor can be manually discharged through a resistor by activating a manual switch.
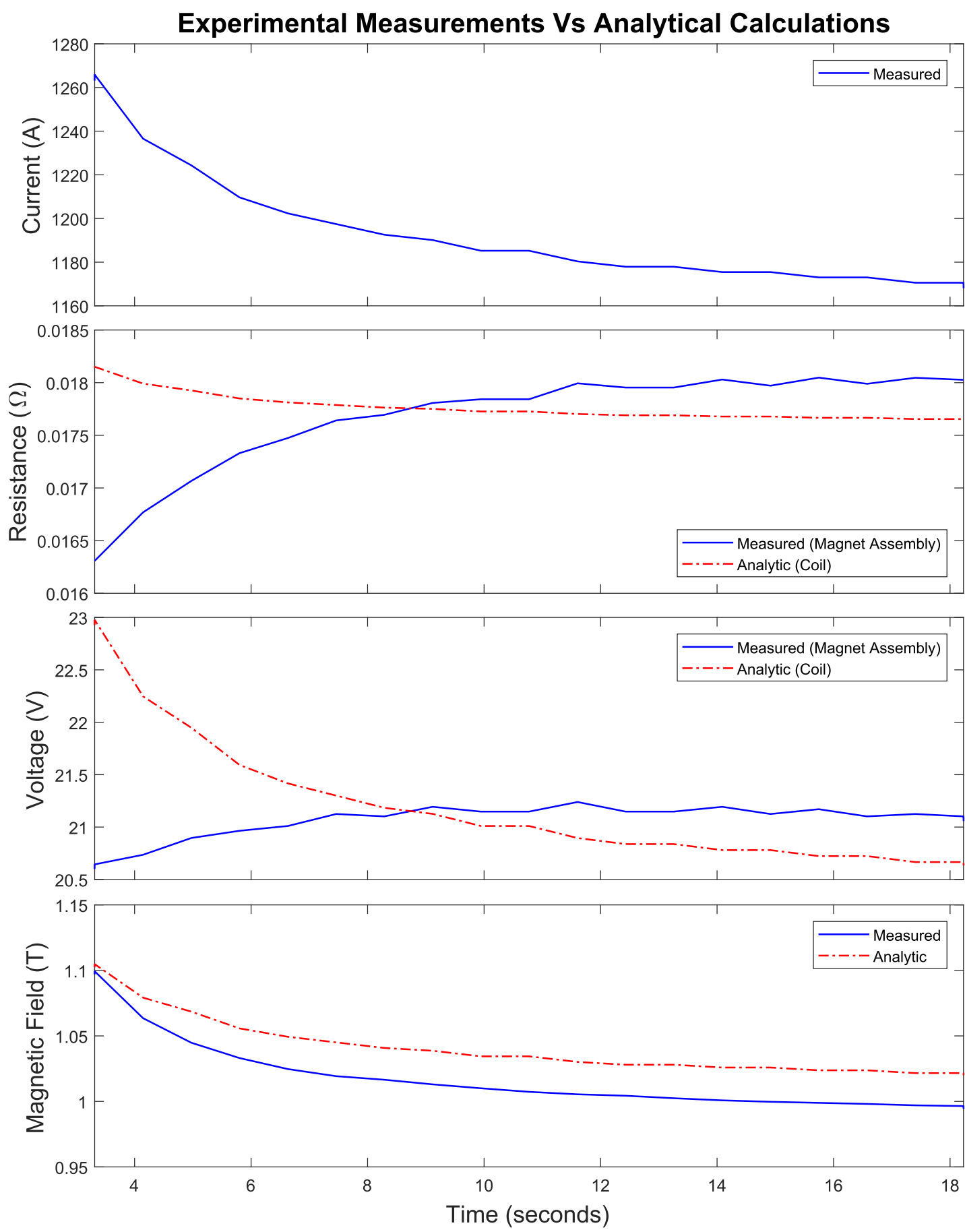

FIG. 9. First panel: experimentally measured operating current of a magnet shot beginning at $3.3 \mathrm{~s}$ and ending at $18.2 \mathrm{~s}$. The analytical cooling holes' wall temperatures and the average conductor temperature are approximated at each time step as a function of the measured operating current. The analytical coil's resistance, in the second panel, is calculated as a function of resistivity at the averaged conductor temperature and is plotted against the measured resistance of the magnet assembly. Third panel: the analytical coil voltage drop is calculated by multiplying the analytical coil resistance by the measured current and is plotted against the measured voltage drop across the magnet assembly. Fourth panel: the analytical magnetic field at the bore's center is calculated for the measured current and is plotted against experimentally measured magnetic fields. 


\section{ANALYTICAL DESIGN VS BETA'S EXPERIMENTAL RESULTS}

Experimental results from BETA's diagnostics show agreement with the analytical design methods. Data from a single shot are shown in Fig. 9, with the SCR pulsed at $3.3 \mathrm{~s}$ and the IGBTs pulsed at $18.2 \mathrm{~s}$, for a total shot duration of $14.9 \mathrm{~s}$. The experimental data are acquired approximately every $800 \mathrm{~ms}$. During the first three seconds of operation, there is an initial current spike, which is due to both the load resistor and magnet reaching operating temperature and resistance.

The coil's analytical resistance, is calculated with Eq. (3) using resistivity, $\rho_{\text {avg }}$, given by Eq. (2). The analytical average conductor temperature, $T_{\text {avg }}$, in Eq. (2) is approximated by averaging the cooling channel's wall temperatures as a function of measured operating current. The analytical and measured resistance of the coil and magnet assembly for the shot duration can be seen in Fig. 9, respectively. The measured resistance is calculated by dividing the measured voltage drop over the magnet assembly by the measured operating current. The measured magnet assembly resistance is larger than BETA's analytical coil resistance at steady state because the magnet assembly is measured across leads that connect the magnet to the SSB. The analytical resistance is only calculated for the coil. The averaged difference between measured and analytical resistance from $12 \mathrm{~s}$ to the end of the pulse duration is $0.33 \mathrm{~m} \Omega$. This resistance difference is approximately the resistance of the magnet's leads under operating conditions. The experimental results show that measuring resistance is one approach that authenticates the thermal solver developed by DPL because coil resistance is a function of both temperature and axial Lorentz force. However, the force applied through the tie rods is much larger than the axial Lorentz force, thus any contact resistance in the magnet coil due to the magnetic forces can be neglected.

The coil's analytical voltage drop is calculated by multiplying the analytical coil's resistance by the measured operating current. The analytical voltage drop in Fig. 9 is a steady state calculation and therefore initially larger than the measured voltage drop until BETA reaches operating temperature and resistance.

The magnetic field plotted in Fig. 9 was measured at the very center of BETA's core. This position was calibrated by connecting BETA to an external current supply and finding the maximum field at $120 \mathrm{~A} \mathrm{DC}$. The average percent error from the measured magnetic field and analytic field is $2.26 \%$ for the pulse duration in Fig. 9. The majority of percentage error is attributed to the deviation from ideal current density due to the linearity of BETA's conductor temperature. Therefore, the magnetic field solvers developed for Bitter magnets at DPL will increase in accuracy when conductor temperature is uniform.

The analytical cooling channel's wall and outlet temperatures at the measured operating current are plotted for the pulse duration in Fig. 10. Water temperature was measured experimentally with K-type thermocouples at the outlet for five cooling channels during the pulse duration. However, there was significant measurement error resultant of both the magnetic field and electrochemical effects which adds to the standard error, $\pm 2.2^{\circ} \mathrm{C}$, of thermocouples. ${ }^{19,20}$ Analytical outlet water temperature of the cooling channels falls within the thermocouple error. New methods of DAQ for experimentally measuring magnet and water temperatures are being investigated with thermochromic liquid crystal paper imaging.

The magnetic field at constant current was also measured along the $+Z$-axis of the bore to compare against both FEA and analytical results in Fig. 11. Both the FEA and analytical fields

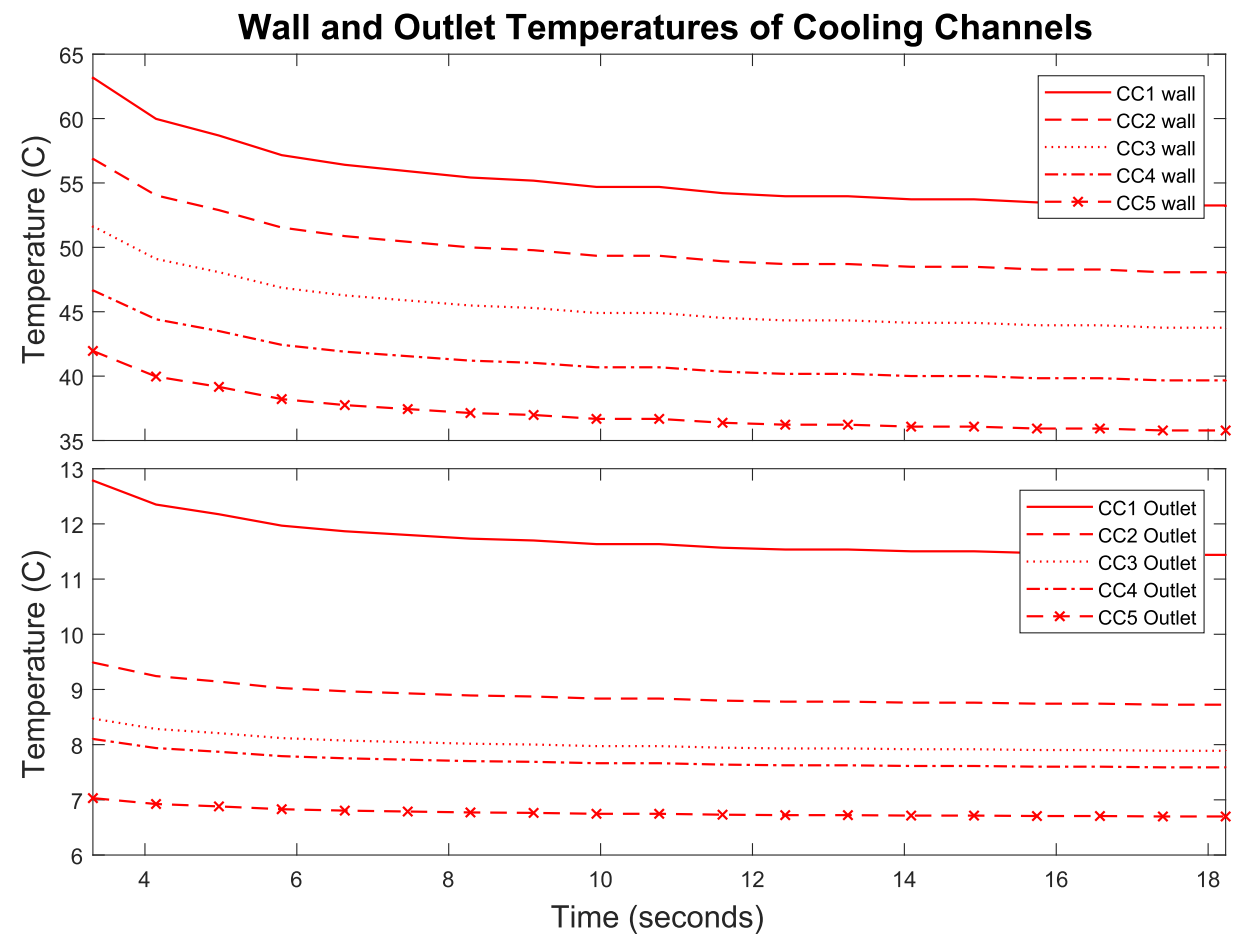

FIG. 10. The analytical temperatures for the cooling channel's wall and outlet water are plotted for the pulsed duration in Fig. 9. 
Magnetic Field Along +Z-axis of Bore

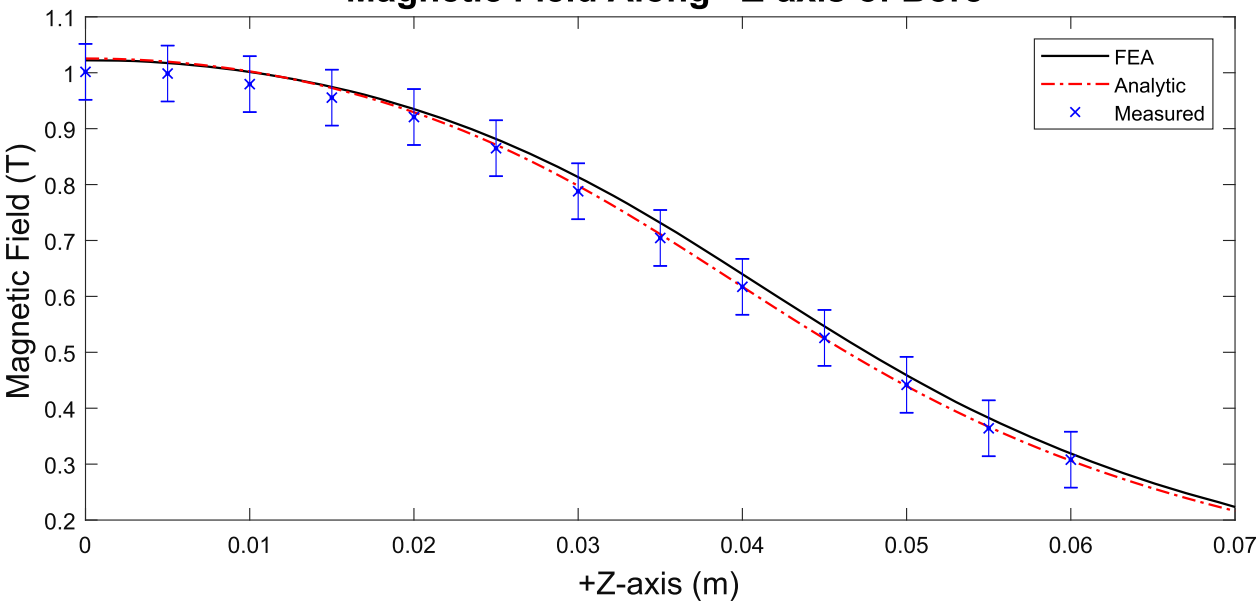

FIG. 11. Magnetic field magnitude from the bore's center along the $+Z$-axis at $1175 \mathrm{~A} \mathrm{DC}$ for the FEA, analytical, and experimental measurements. were evaluated at 1175 A DC. The experimental data consist of multiple magnet shots at different distances along the center of the bore. The measured magnetic field closest to 1175 A DC over the shot duration is plotted in the figure with error bars of $5 \%$, which is the propagated measurement error. The average percent difference between the analytical and FEA estimates for the magnetic field magnitude along the bore of BETA is $1.15 \%$. The average percent difference between experimental and FEA is $2.86 \%$ and between experimental and analytical is $1.11 \%$.

\section{CONCLUSIONS}

BETA's magnet core and vessel design are new simplified methods for producing Bitter magnets. The cooling and electrical system is designed to be scalable for dissipating more

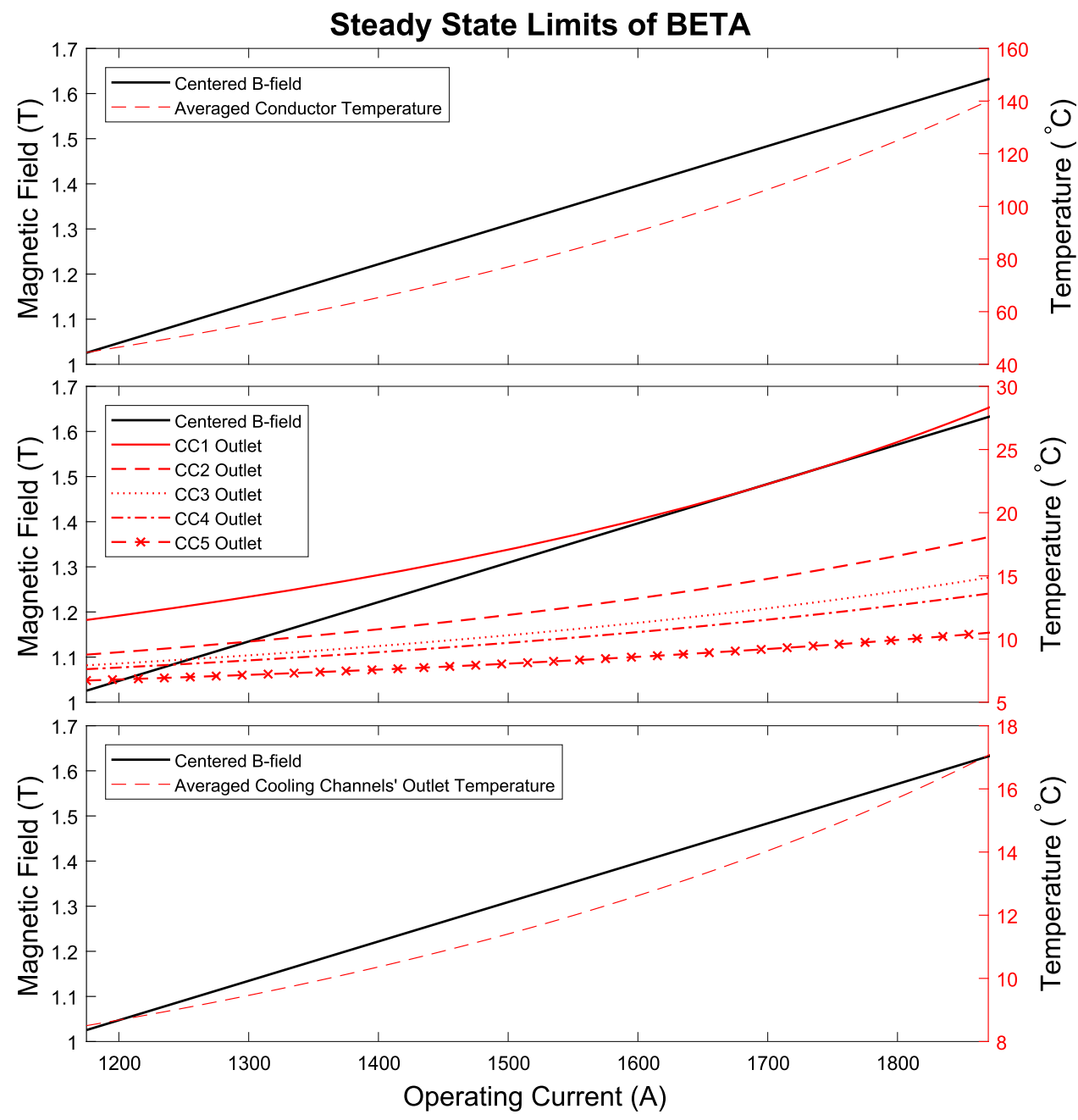

FIG. 12. Analytical steady state limitations in terms of BETA's average conductor temperature and the outlet water temperatures of the cooling channels for varying currents and magnetic fields. Currents are plotted from the operating current of $1175 \mathrm{~A}$ to the current limit of $1870 \mathrm{~A}$. In the last plot, the cooling channels' outlet water temperatures are averaged to represent bulk water temperature at the coil's bottom. 
power and breaking higher currents. BETA's design can reach steady state magnetic fields higher than $1 \mathrm{~T}$ by using faster flow rates in the cooling system. BETA's steady state operation is limited by the maximum temperature of the insulator G10-FR4 which is $140{ }^{\circ} \mathrm{C}$. For our cooling system's mass flow rate, the average conductor temperature will reach $140{ }^{\circ} \mathrm{C}$ at $1870 \mathrm{~A}$. A centered magnetic field of $1.63 \mathrm{~T}$, an averaged cooling channel exit temperature of $17{ }^{\circ} \mathrm{C}$, and a FOS of 61.1 will be maintained at this current. Varying parameters for BETA can be found in Fig. 12 from the operating current of 1175 A to the current limit of $1870 \mathrm{~A}$. Furthermore, BETA is currently in use for conducting plasma stability experiments at UMBC.

The analytical design methods developed to construct Bitter magnets for magnetized dusty plasma experimentation have been proven reliable with the completion of BETA. These design methods were developed for fast design iteration over conventional and FEA methods. BETA's experimental data validate and verify these design methods and will be used to develop the successor magnet, ALPHA.

\section{ACKNOWLEDGMENTS}

We would like to acknowledge the Special Research Assistantship/Initiative Support and the Department of Mechanical Engineering at UMBC for supporting this research.

\section{NOMENCLATURE}

\section{Magnetic field design}

$\lambda_{\text {Filling } \quad \text { Filling factor of Bitter arc }}$

$B \quad$ Bitter magnet's field amplitude

I Coil's current

$L \quad$ Coil's inductance

$l \quad$ Coil's length

$N \quad$ Number of magnetic turns in the coil

$N_{\mathrm{c}} \quad$ Number of conductors in the coil

$P \quad$ Coil's electrical power

$R \quad$ Coil's resistance

$r_{1} \quad$ Bitter arc's inner radius

$r_{2} \quad$ Bitter arc's outer radius

$t \quad$ Bitter arc thickness

$V_{0} \quad$ Voltage drop over a single conducting Bitter arc

$V_{t} \quad$ Voltage drop over coil

\section{Mechanical stress design}

$\begin{array}{ll}\epsilon_{\text {eq,avg }} & \text { Averged equivalent elastic strain } \\ \epsilon_{\text {eq,max }} & \text { Maximum equivalent elastic strain } \\ \sigma_{v, \text { avg }} & \text { Averaged equivalent Von Misses stress }\end{array}$

$\begin{array}{ll}\sigma_{v, \max } & \text { Maximum equivalent Von Misses stress } \\ F_{\text {body,max }} & \text { Maximum body force density } \\ x_{\text {total,avg }} & \text { Averaged total deformation } \\ x_{\text {total,max }} & \text { Maximum total deformation } \\ \text { FOS } & \text { Factor of safety for equivalent stress }\end{array}$

\section{Thermal design}

$\dot{m} \quad$ Water's mass flow rate through cooling channels

A Cross-sectional area and normal to water flow of cooling channels

$h \quad$ Heat transfer coefficient

$r_{p} \quad$ Centered radial placement of cooling channels

$T_{\text {outlet }} \quad$ Analytical cooling channel outlet's water temperature

$T_{\mathrm{w},(\mathrm{FEA})} \quad$ FEA averaged cooling channel wall temperature

$T_{\mathrm{w}} \quad$ Analytical cooling channel wall temperature

$v_{p} \quad$ Water's velocity through cooling channels

${ }^{1}$ W. J. Birmingham, E. M. Bates, and C. A. Romero-Talamas, J. Therm. Sci. Eng. Appl. 8, 021008 (2015).

${ }^{2}$ E. M. Bates, W. J. Birmingham, and C. A. Romero-Talamas, IEEE Trans. Magn. 53, 1 (2017).

${ }^{3}$ F. Bitter, Rev. Sci. Instrum. 10, 373 (1939).

${ }^{4}$ C. A. Romero-Talamas, E. M. Bates, W. J. Birmingham, and W. F. Rivera, IEEE Trans. Plasma Sci. 44, 535 (2016).

${ }^{5}$ E. Thomas, R. Merlino, and M. Rosenberg, Plasma Phys. Controlled Fusion 54, 124034 (2012).

${ }^{6}$ E. M. Bates, W. J. Birmingham, and C. A. Romero-Talamas, IEEE Trans. Plasma Sci. 44, 540 (2016).

${ }^{7}$ B. Gao, H.-J. Schneider-Muntau, Y. Eyssa, and M. Bird, IEEE Trans. Magn. 32, 2503 (1996).

${ }^{8}$ M. Bird, Supercond. Sci. Technol. 17, R19 (2004).

${ }^{9}$ D. B. Montgomery, in Solenoid Magnet Design: The Magnetic and Mechanical Aspects of Resistive and Superconducting Systems (Wiley-Interscience, New York, 1969), Chap. 4.

${ }^{10}$ Y. Nakagawa, IEEE Trans. Magn. 17, 1786 (1981).

${ }^{11}$ V. Lisejkin, Grid Generation Methods (Springer, Berlin, 1999), pp. $101-130$.

${ }^{12}$ W. M. Kays and M. E. Crawford, in Convective Heat and Mass Transfer, 3rd ed. (McGraw-Hill, New York, 1993), Chap. 14.

${ }^{13}$ F. Wijnen, S. Wiegers, J. van Velsen, J. Rook, A. Ouden, J. Perenboom, and N. Hussey, IEEE Trans. Appl. Supercond. 26, 1 (2016).

${ }^{14}$ C. F. Colebrook, T. Blench, H. Chatley, E. Essex, J. Finniecome, G. Lacey, J. Williamson, and G. Macdonald, J. Inst. Civ. Eng. 12, 393 (1939).

${ }^{15}$ B. Pollock, D. Froula, P. Davis, J. Ross, S. Fulkerson, J. Bower, J. Satariano, D. Price, K. Krushelnick, and S. Glenzer, Rev. Sci. Instrum. 77, 114703 (2006).

${ }^{16}$ T. Basler, J. Lutz, R. Jakob, and T. Bruckner, in International MultiConference on Systems, Signals and Devices, 2012.

${ }^{17}$ J. Zyborski, J. Czucha, and M. Sajnacki, Proc. Inst. Electr. Eng. 123, 685 (1976).

${ }^{18}$ T. Ding, J. Wang, H. Ding, L. Li, B. Liu, and Y. Pan, IEEE Trans. Appl. Supercond. 22, 5400404 (2012).

${ }^{19}$ S. Beguš, J. Bojkovski, J. Drnovšek, and G. Geršak, Meas. Sci. Technol. 25, 035006 (2014).

${ }^{20}$ J. Middlehurst, P. W. Board, and R. G. P. Elbourne, J. Sci. Instrum. 41, 676-678 (1964). 